\title{
A long term review of augmentation mastopexy in muscle splitting biplane
}

\author{
Umar Daraz Khan \\ Aesthetic Plastic Surgeon, Reshape House, West Malling, Kent ME19 6QR, UK.
}

Address for correspondence: Dr. Umar Daraz Khan, Aesthetic Plastic Surgeon, Reshape House, 2-4 High Street, West Malling, Kent ME19 6QR, UK. E-mail: Mrumarkhan@aol.com

\begin{abstract}
Aim: Simultaneous or single stage mastopexy with augmentation is challenging, unique and commonly performed by a plastic surgeon. In this procedure pocket for implant placement, marking for envelope reduction and type of implants used can affect the outcome of the procedure. Muscle splitting pocket for mastopexy is a plane described by the author for implant placement with a short term follow up. The use and outcome of the technique is presented with a larger series and a long term follows up to evaluate the efficacy of the procedure. Methods: Retrospective data was collected. Augmentation was performed using muscle splitting technique and periareolar, vertical scar and wise pattern were used for skin reduction and mastopexy. A single surgeon performed all procedures. Results: In total 108 patients mastopexy with augmentation in muscle splitting technique. The mean age of the patient was 32.2 years (range: 18-67 years) with an average follow up of 4.5 years (range: 3 months to 10 years). All patients had round textured cohesive gel silicone implants with a mean size of 308 cc (range: $200-555$ cc). Wound infection was seen in $4(3.7 \%)$, wound breakdown in $7(6.5 \%)$ patients. Drains were used in 25 $(23.1 \%)$. All patients were treated as day cases and revision surgery was performed in $12(11.1 \%)$. There was no hematoma, deep venous thrombosis (DVT) or nipple areolar complex in the series. Conclusion: Simultaneous augmentation mastopexy in muscle splitting pocket can be performed with good aesthetic results along with an acceptable revision rate.
\end{abstract}

Key words:

Augmentation mastopexy; muscle splitting mastopexy; muscle splitting augmentation; submuscular augmentation mammoplasty

\section{INTRODUCTION}

Augmentation mammoplasty for volume enhancement and mastopexy for ptosis correction is commonly performed as a simultaneous procedure by aesthetic plastic surgeons. In this procedure, envelope markings, type of implants and the pocket for implant placement can affect the outcome the result. Breast implants can be placed in front ${ }^{[1]}$ or behind ${ }^{[2]}$ the pectoralis muscle. Skin reduction is commonly performed using periareolar, ${ }^{[3]}$ wise pattern, ${ }^{[4]}$ vertical scar $^{[5]}$ or its

\begin{tabular}{|l|l|}
\hline \multicolumn{2}{|c|}{ Access this article online } \\
\hline Quick Response Code: & Website: \\
\hline & http://par.oaepublish.com/ \\
\cline { 2 - 2 } & \\
\hline
\end{tabular}

modifications. ${ }^{[6]}$ The two procedures are totally independent of each other. ${ }^{[7,8]} \mathrm{A}$ low complication rate is reported when each component performed separately. However when these two components are done as a simultaneous procedure, it was considered very challenging with a warning to surgeons. ${ }^{[9]}$ A revision rate of $16.7 \%$ was reported when the operation was performed as a single stage procedure

This is an open access article distributed under the terms of the Creative Commons Attribution-NonCommercial-ShareAlike 3.0 License, which allows others to remix, tweak and build upon the work non-commercially, as long as the author is credited and the new creations are licensed under the identical terms.

For reprints contact: service@oaepublish.com

How to cite this article: Khan UD. A long term review of augmentation mastopexy in muscle splitting biplane. Plast Aesthet Res 2016;3:21-5.

Received: 08-05-2015; Accepted: $11-11-2015$ 
than revision rates of $8.6 \%$ for mastopexy and $10.7 \%$ for augmentation mammoplasty performed separately. ${ }^{[10,11]}$ For this reason single stage augmentation mastopexy remains a very challenging procedure for surgeons and often done in stages. The use of muscle splitting submuscular technique for mastopexy with augmentation with earlier results has been described before. ${ }^{[7]}$ The current article includes a larger series with longer follow up to compare early and long term results and to evaluate the efficacy of the procedure.

\section{METHODS}

Retrospective data was collected using patient's charts. All patients who had simultaneous augmentation mastopexy in muscle splitting biplane using round cohesive gel textured silicone implants performed by author were selected.

All patients were operated under general anesthetic with full muscle relaxation and with their arms abducted and supported at an angle less than 90 degree. A single dose of intravenous cephalosporin was given to all patients at induction time. Periareolar, vertical or wise pattern scars were used for augmentation mastopexy depending on the preoperative measurements and wishes of the patient. Muscle splitting submuscular pocket was used for implant placement and procedure is performed as a day case. Drains were used in the earlier part of the study period. All patients wore support brassiere for three weeks as a routine.

Earlier complications related to wound infection, wound breakdown, haematoma, periprosthetic infection, use of drains and size of the implants were analyzed. Patients who had their implants placed in subglandular or partial submuscular pockets were excluded from the series.

\section{RESULTS}

Between 2005 and 2015 augmentation mastopexy was performed in 108 patients. Mean age of the patient was
32.2 years (range: 18-67 years) with an average follow up of 4.5 years (range: 3 months to 10 years). All patients had round textured cohesive gel silicone implants with a mean size of $308 \mathrm{~mL}$ (range: 200-555 mL). Mean size of implants in periareolar mastopexy, vertical scar and wise pattern mastopexy was $327 \mathrm{~mL}$ (range: 170-555 $\mathrm{mL}$ ), $277 \mathrm{~mL}$ (range: 200-525 mL), $252 \mathrm{~mL}$ (range: 200-300 mL) respectively. Nipple-areolar complex (NAC) repositioning were predominantly performed using medially based flaps. Majority of the patient requiring mastopexy presented with varying degree of bilateral class A to $C$ ptosis (66.7\%) and a combination of ptosis (17.6\%). Mean preoperative suprasternal notch (SN) to NAC distance was $24.3 \mathrm{~cm}$ (range: 19-31 cm). Mean neo NAC was marked at $21.4 \mathrm{~cm}$ (range: $18.5-25 \mathrm{~cm}$ ) from suprasternal notch using inframammary crease (IMC) as a reference. Mean postoperative suprasternal notch to NAC distance was $20.8 \mathrm{~cm}$ (range: 18-24.5 cm). Mean preoperative NAC to IMC distance was $8.9 \mathrm{~cm}$ (range: 4.5-14 cm). Mean postoperative NAC to IMC distance $9.7 \mathrm{~cm}$ (range: $6.0-12.5 \mathrm{~cm}$ ).

Mild to moderate wound infection noted in $4(3.7 \%)$ and minor wound breakdown were seen in 7 (6.5\%) patients respectively. Drains were used in $25(23.1 \%)$ and there was no NAC necrosis, hematoma or DVT.

Revision surgery was performed in $12(11.1 \%)$ patients. The most common reason for revision surgery was for redundant skin excision at lower pole (16.7\%) and vertical scar touch up (16.7\%).

\section{Case I}

A 31-year-old admin worker presented with a class $C$ ptosis without a history of breast volume loss, weight loss or pregnancy. On examination her breast cup size was $34 \mathrm{D}$ with a breast width of $15 \mathrm{~cm}$ each side. Her sternal notch to NAC distance was $24 \mathrm{~cm}$ and NAC to IMC distance of $9 \mathrm{~cm}$ respectively. She was interested in going bigger but
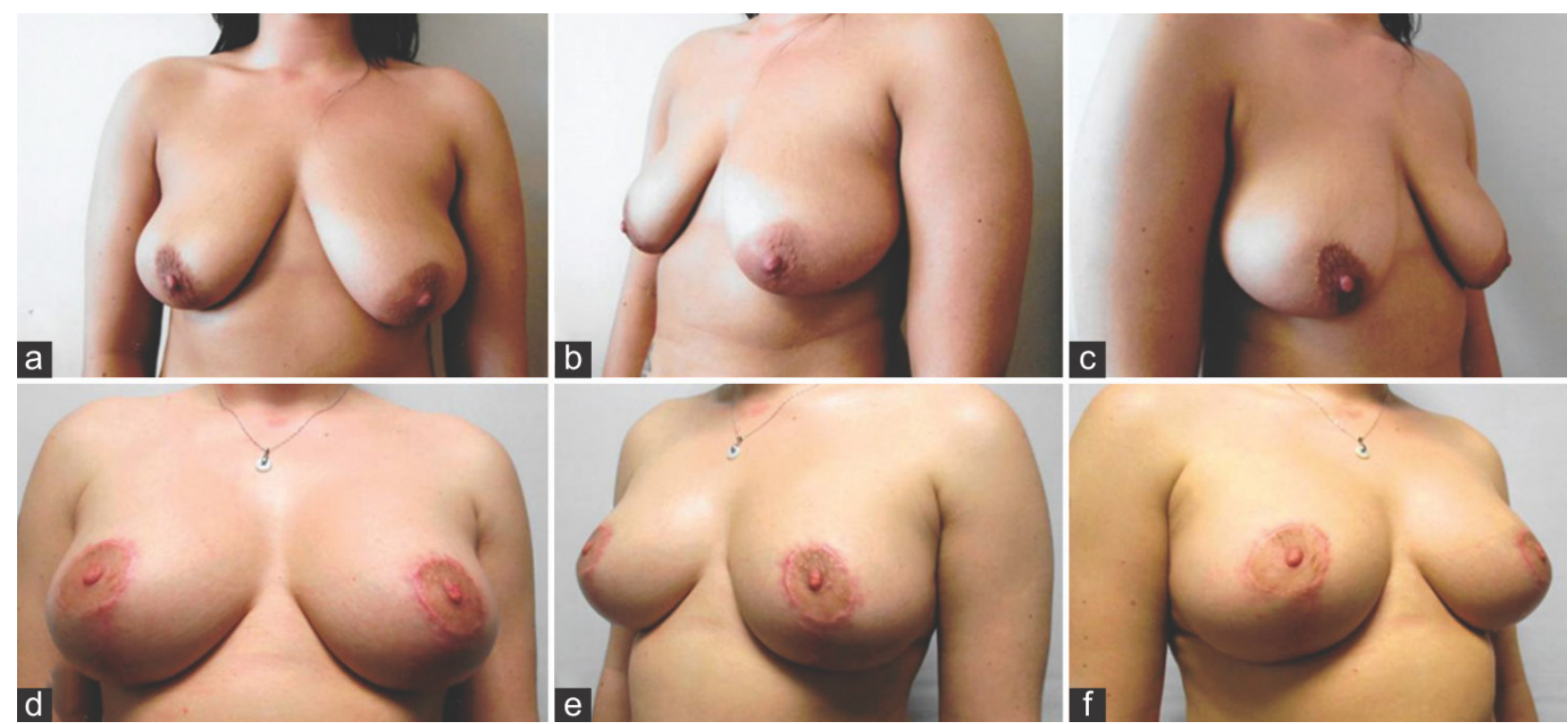

Figure 1: (a-c) Preoperative views of a 31-year-old patient with grade $\mathrm{C}$ ptosis; (d-f) four months' postoperative views showing results following vertical scar augmentation mastopexy with $250 \mathrm{~mL}$ moderate profile textured round cohesive gel silicone implants 

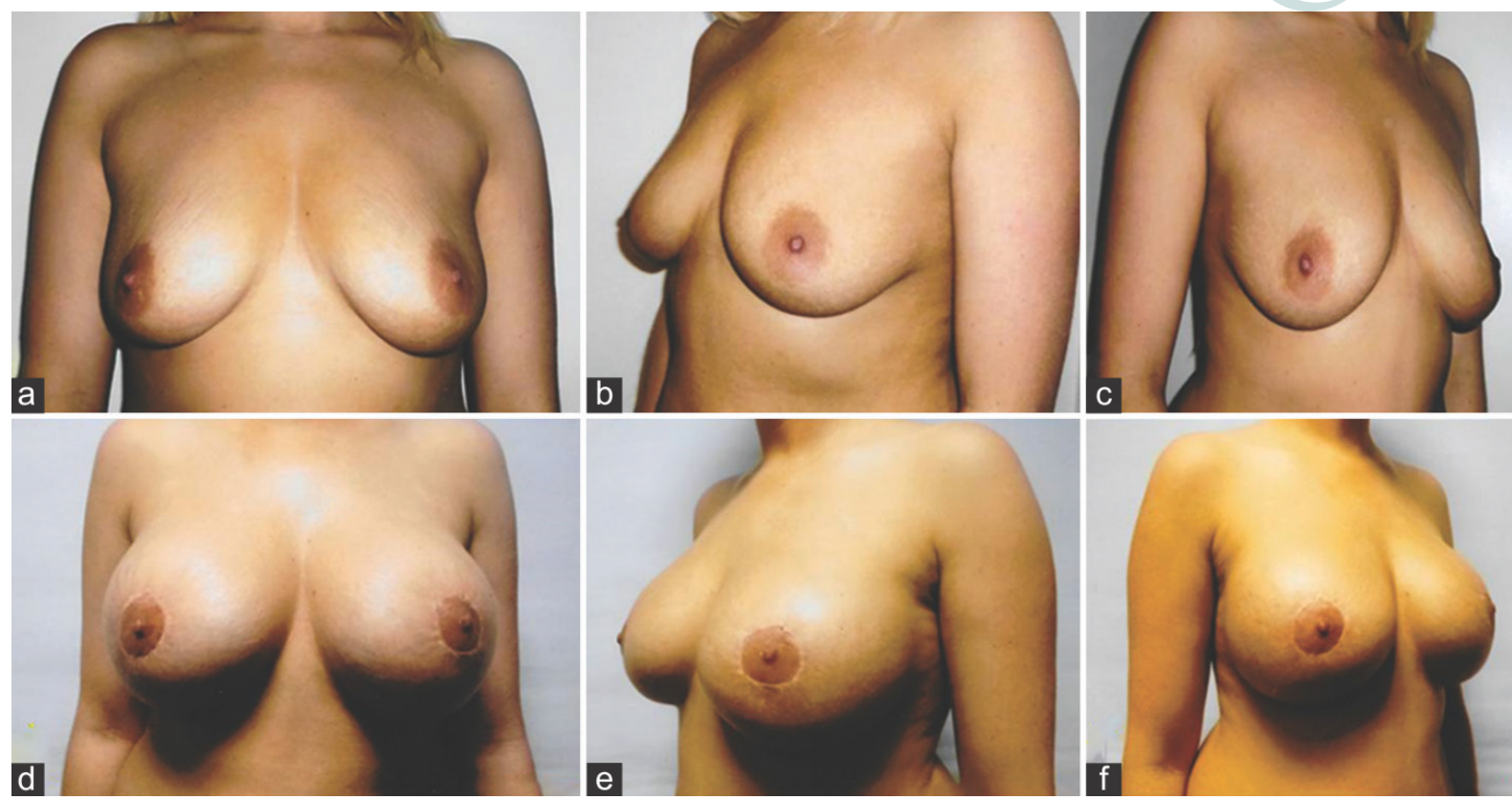

Figure 2: (a-c) Preoperative views of a 29-year old patient with grade B ptosis; (d-f) six months' postoperative views showing results following periareolar augmentation mastopexy with $400 \mathrm{~mL}$ high profile textured round cohesive gel silicone implants
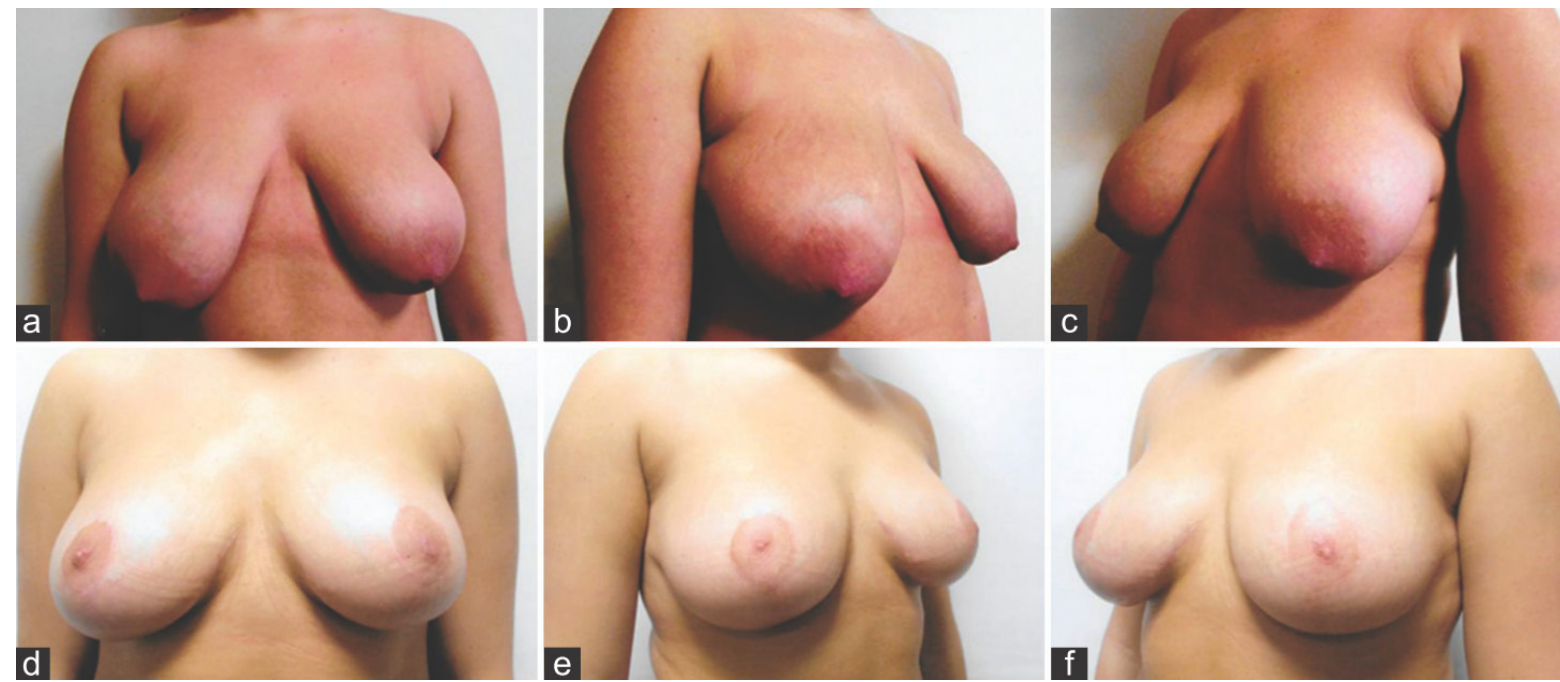

Figure 3: (a-c) Preoperative views of a 20-year old patient with severe grade C ptosis; (d-f) one year's postoperative views showing results following wise pattern augmentation mastopexy using $225 \mathrm{~mL}$ moderate profile textured round cohesive gel silicone implants

not more than a cup size and her main concern was the droopy looking breasts [Figure 1a-c]. A vertical scar cat's tail modification was selected for the NAC mobilization and envelope reduction and muscle splitting pocket was selected to place $250 \mathrm{~mL}$ Mentor Siltex Cohesive II Moderate profile implants. Her new NAC was marked $20 \mathrm{~cm}$ using IMC as the reference. Excised breast tissue weighed $63 \mathrm{~g}$ on her right and $69 \mathrm{~g}$ on her left side. Her one-year postoperative measurements showed a breast cup size of $34 \mathrm{DD}$ and sternal notch to NAC and NAC to IMC distance of $19.5 \mathrm{~cm}$ and 10 $\mathrm{cm}$ respectively. Patient did develop bilateral hypertrophic scarring of NAC for which she was initially treated with silicone gel application and later with intra-lesional steroids injections [Figure 1d-f].

\section{Case 2}

A 29-year-old beautician and a mother of two children aged 12 and 7 , booked a consultation for breast remodeling surgery. Her breast cup size was measured 36 B along with Class B ptosis. Her preoperative SN to NAC measurements was $23 \mathrm{~cm}$ and nipple to IMC distance was measured $8 \mathrm{~cm}$ respectively. She used to be $36 \mathrm{DD}$ prior to her pregnancies and was interested in regaining similar breast volume and cup size. To achieve desired cup size, $400 \mathrm{~mL}$ round extra high profile Allergan Natrelle INSPIRA TRX textured cohesive silicone implant were selected. Her grade B class ptosis with an adequate skin envelope and a reasonable nipple to inframammary crease position did not require skin envelope reduction; a moderate nipple elevation using periareolar markings was considered reasonable [Figure 2a-c]. Her new NAC was marked at $20.5 \mathrm{~cm}$ using IMC as the reference for an adequate new NAC position and projection. She had her breast implants placed in muscle splitting biplane submuscular pocket. Her one year postoperative cup size was $36 \mathrm{DD}$ with sternal notch to NAC distance of $22 \mathrm{~cm}$ and NAC to IMC distance of $11 \mathrm{~cm}$ [Figure 2d-f]. 


\section{Case 3}

A 20-year-old young adult female was seen for a severe developmental ptosis along with a very noticeable breast size asymmetry. Patient has no history of childbirth or loss of weight or breast volume loss since puberty. She was wearing a $34 \mathrm{E}$ brassiere and her sternal notch to NAC distance was measured $28 \mathrm{~cm}$ on her right and $26 \mathrm{~cm}$ on her left side with a breast width of $14 \mathrm{~cm}$ on both sides. Her NAC to IMC distance was measured $13 \mathrm{~cm}$ on her right and $10 \mathrm{~cm}$ on her left side respectively with a bilateral Class $C$ ptosis [Figure 3a-c]. Patient was not interested in going any bigger than her current size. Mentor $225 \mathrm{~mL}$ Siltex cohesive II moderate profile implants were chosen to be placed in muscle splitting biplane pocket to replace the anticipated breast tissue reduction. Medially based flap with wise pattern markings were used to reduce preoperative inframammary mammary crease distance, NAC repositioning and envelope and breast reduction. New NAC was marked at $20 \mathrm{~cm}$ using IMC as a reference, $273 \mathrm{~g}$ of tissue was removed from right and 247 $\mathrm{g}$ tissue was excised from her left breast. Her ten month cup size was 34 DD with sternal notch to NAC distance of $20 \mathrm{~cm}$, NAC to IMC distance of $9.5 \mathrm{~cm}$ bilaterally with good size symmetry [Figure 3d-f].

\section{DISCUSSION}

Selection of implant pocket, markings for breast envelope reduction and orientation of flap in simultaneous augmentation mastopexy are independent to each other and can be selected in any combination. The use of combination may affect the outcome with a variable rate of revision surgery. ${ }^{[7]}$ Despite the various safety issues encountered in the recent past, ${ }^{[12]}$ cohesive gel silicone breast implant remains the first choice for the volume replacement. In majority of the patients presenting with hypoplasia, requests for volume restoration in early type A ptosis, intended results are successfully achieved using breast implants with wellconcealed scars. However more advanced ptosis necessitates the NAC repositioning with some sort of skin reduction. The NAC repositioning can be achieved using periareolar, vertical scar or wise pattern markings depending on the skin excess and degree of ptosis. In current series $66.7 \%$ of the patients presented with varying degree of class A to $C$ ptosis and $17.6 \%$ of patients presented with varying combination of ptosis on

Table 1: Causes for mastopexy with augmentation in 108 patients

\begin{tabular}{cc}
\hline Cause for mastopexy & $\boldsymbol{n}(\%)$ \\
\hline Class A ptosis & $6(5.6)$ \\
Class B ptosis & $22(20.4)$ \\
Class C ptosis & $35(32.4)$ \\
Combination of A and C ptosis & $2(1.9)$ \\
Combination of A and B ptosis & $3(2.8)$ \\
Combination of B and C ptosis & $14(13)$ \\
Pseudoptosis & $9(8.3)$ \\
Loose skin & $2(1.9)$ \\
Tuberous breasts & $2(1.9)$ \\
Others & $12(11.2)$ \\
\hline
\end{tabular}

two sides [Table 1]. Selection of markings for skin reduction is paramount to achieve an aesthetically pleasing natural breast with normal breast morphometry, comparable to the results seen following augmentation mammoplasty with an implant alone. ${ }^{[13]}$ In authors' opinion, use of periareolar or vertical scar markings in patients presenting with excess IMC to NAC measurements are likely to end with bottoming out following simultaneous mastopexy with augmentation. Regardless of the degree of ptosis, type of skin markings for nipple elevation and mastopexy should ideally be based on the preoperative NAC to IMC measurements. ${ }^{[13]}$ When mastopexy is performed with vertical scar or wise pattern, the use of larger implant size selection may be restricted. Use of larger implant placements with these markings, is likely to result in complication namely skin and wound breakdown mainly due to pressure exerted by implant on reduced skin envelope. In current series, mean size of the implants used in the series is $308 \mathrm{~mL}$ but when looked into the mean size of the implants used in three types of mastopexies, the results were interesting. Mean size of the implants was considerably and significantly larger in periareolar mastopexies than the mean size of the implants used in vertical and wise pattern mastopexies [Table 2].

A high complication rate has been reported when the procedure is combined together as simultaneous mastopexy with augmentation. ${ }^{[14]}$ The author has reported a revision rate of $9 \%$ in an earlier report on mastopexy in muscle splitting biplane. ${ }^{[7]}$ The current series with long-term results have shown a revision rate of $11.1 \%$, up by nearly $2 \%$ when compared with author's earlier series. The most common reason for revision being the excision of redundant skin in 2 patients (16.7\%) and vertical scar touch up in 2 patients (16.7\%) [Table 3]. The revision rate of $11.1 \%$ after 10 years follow-up is acceptable and comparable with the published revision rate of $16.7 \%$ in simultaneous mastopexy with augmentation and lower than $20 \%$ revision rate within five years following augmentation mammoplasty alone using saline-filled implants. ${ }^{[10]}$

Table 2: Implants sizes used in three different types of mastopexies

\begin{tabular}{lccc}
\hline Procedure & \multicolumn{2}{c}{ Implant Size } \\
\hline & $\boldsymbol{n}$ & Range $(\mathbf{m L})$ & Mean \pm SD $(\mathbf{m L})$ \\
Periareolar & 54 & $170-555$ & $327 \pm 73.7$ \\
Vertical scar & 45 & $200-525$ & $277 \pm 62.7$ \\
Wise pattern & 9 & $230-300$ & $252 \pm 29.9$ \\
\hline
\end{tabular}

SD: standard deviation

Table 3: Reasons for revision surgery performed in mastopexy with augmentation

\begin{tabular}{lc}
\hline Reason for revision & $\boldsymbol{n}(\%)$ \\
\hline Dog ear bilateral & $2(16.7)$ \\
Dog ear unilateral & $2(16.7)$ \\
Areolar scar revision & $2(16.7)$ \\
Periareolar to vertical scar conversion & $2(16.7)$ \\
Nipple level asymmetry & $1(8.3)$ \\
Capsular contracture & $1(8.3)$ \\
Vertical scar revision & $1(8.3)$ \\
Bottoming out & $1(8.3)$ \\
\hline
\end{tabular}


The breast implant in augmentation mastopexy can be placed in front or behind the pectoralis muscle. Muscle splitting pocket, where implant lies in front and behind the muscle, has been described for augmentation mammoplasty and simultaneous mastopexy with augmentation. ${ }^{[7,15]}$ The pocket provides muscle cover to the implant in the upper part of the breast leaving lower split pectoralis behind the implant without being detached from the ribs. The advantages of this pocket are many and include undisturbed muscle origin that prevents animation deformity, implant gets locked up and laterally in between two split slips of pectoralis preventing implant's upward or lateral displacement. Intact skin and muscle interface in the upper part of the pocket maintain the vascular territories of the perforators arising from the internal mammary and thoracoacromial axis. ${ }^{[7]}$ These muscular perforators maintain undisturbed blood supply to the NAC flaps and are severed during subglandular pocket increasing vulnerability of NAC flaps. Medially based flap is the author's choice and to date there is no nipple areolar loss due to vascular compromise. The author has reported a revision rate of $1.2 \%$ in an earlier report when muscle splitting pocket was used for implant placement in muscle splitting augmentation when compared to $9.6 \%$ and $20 \%$ revision rate of silicone gel and saline implants respectively. ${ }^{[10,16,17]}$

In a previously published article, author has suggested that periareolar mastopexy should best be limited to a breast where there is an inadequate skin envelope with NAC to IMC distance of less than $5 \mathrm{~cm} \cdot{ }^{[13]}$ Vertical scar selection for mastopexy is likely to give best aesthetic appearance when preexisting NAC to IMC distance is between $5-8 \mathrm{~cm}$. In breasts where NAC to IMC distance is $9 \mathrm{~cm}$ or more, reduction of the vertical limb of the scars is essential for an acceptable NAC to IMC distance otherwise bottoming out is likely to result. Periareolar mastopexy can allow a larger implant to be placed due to the absence of vertical or vertical and transverse skin resection and can allow a far more freedom of implant size selection. However, periareolar mastopexy should be carefully selected, as it is a nipple elevation procedure rather than a skin reduction procedure. This type of mastopexy is best used in selected patients especially in smaller breasts with deficient lower pole skin regardless of the degree of ptosis or in patients with class A ptosis regardless of the skin envelope. Too ambitious use of periareolar markings in advanced ptosis along with skin excess may results in scar stretching associated with flattened nipple areolar complex and an inadequate skin envelope reduction. A high number of revision surgery is reported when periareolar mastopexy has been used for mastopexy with augmentation. ${ }^{[10,18]}$ Similarly when vertical mastopexy was used as "All-Season" markings, 28\% skin redundancy and persistent ptosis was reported. ${ }^{[11]}$
In conclusion, single stage mastopexy with augmentation in muscle splitting biplane pocket along with appropriate use of markings for skin reduction and careful implant size selection keep the complication and revision rate of the revision surgery within an acceptable range.

\section{Financial support and sponsorship}

Nil.

\section{Conflicts of interest}

There are no conflicts of interest.

\section{REFERENCES}

I. Biggs TM, Yarish R.S. Augmentation mammoplasty: A comparative analysis. Plast. Reconstr Surg 1990;85:368-372

2. Regnault P. Partially submuscular breast augmentation. Plast Reconstr Surg 1977;59:72-6

3. Binelli L. A new periareolar mammoplasty: the "round block" technique. Aesthetic Plast Surg 1990; 14:93-100.

4. Wise RL.A preliminary report on a method of planning the mammoplasty. Plast Reconstr Surg (1946) 1956; 17:367-75.

5. Lejour M.Vertical mammoplasty and liposuction of the breast. Plast Reconstr Surg 1994;94:100-14.

6. Khan UD. Vertical scar mastopexy with cat's tail extension for prevention of skin Redundancy: an experience with 17 consecutive cases after mastopexy and mastopexy with breast augmentation. Aesthetic Plast Surg 2012;36:303-307.

7. Khan UD. Augmentation mastopexy in muscle-splitting biplane: outcome of first 44 consecutive cases of mastopexies in a new pocket. Aesthetic Plast Surg 2010;34:313-321.

8. Khan UD. Vertical scar with the bipedicle technique: a modified procedure for breast reduction and mastopexy. Aesthetic Plast Surg 2007;31:337-342.

9. Spear S. Augmentation/mastopexy: "Surgeon, beware". Plast Reconstr Surg 2003: I 12:905-6

10. Stevens WG, Stoker DA, Freman ME, Quardt SM, Hircsh EM, Cohen R. Is one-stage breast augmentation with mastopexy safe and effective? A review of I86 primary cases. Aesthet Surg J 2006;26:674-8I.

II. Swanson E. Prospective comparative clinical evaluation of 784 consecutive cases of breast augmentation and vertical mammoplasty, performed individually and in combination. Plast Reconstr Surg 2013;132:30e-45e.

12. Khan UD. Poly Implant Prothèse (PIP) incidence of device failure and capsular contracture: a retrospective comparative analysis. Aesthetic Plast Surg 2013;37:906-I3.

13. Khan UD.Aesthetic surgery of the breast. In: Mugea TT, Shiffman MA, editor. Use of nipple-areolar to inframammary crease mesurments to reduce bottoming out following augmentation mastopexy. Berlin: Springer; 20I5. p. 649-56.

14. Spear SL, Low M, Ducic I. Revision augmentation mastpexy: indications, operations, and outcomes. Ann Plast Surg 2003;5 I:540-6.

15. Khan UD. Muscle-splitting breast augmentation: a new pocket in a different Plane. Aesthetic Plast Surg 2007;31:553-558.

16. Khan UD. Muscle-splitting, subglandular, and partial submuscular augmentation mammoplasties: a 12-year retrospective analysis of 2026 primary cases. Aesthetic Plast Surg 2013;37:290-302.

17. Calobrace MB, Herdt DR, Cothron KJ. Simultaneous augmentation/ mastopexy: a retrospective 5-year review of 332 consecutive cases. Plast Reconstr Surg 2013;131:145-56.

18. Stevens WG, Freeman ME, Stoker DA, Quardt SM, Cohen R, Hirsch EM. One-stage mastopexy with breast augmentation: a review of 321 patients. Plast Reconstr Surg 2007; I20:1674-9. 